\title{
Rod-shaped silver supercluster unveiling strong electron coupling between substituent icosahedral units
}

Shang-Fu Yuan, ${ }^{\dagger}$ Cong-Qiao Xu, ${ }^{*}{ }^{\ddagger}$ Wen-Di Liu, ${ }^{\dagger}$ Jing-Xuan Zhang, ${ }^{\ddagger}$ Jun Li ${ }^{\dagger,}$ and Quan-Ming Wang*, ${ }^{\dagger}$

Department of Chemistry, Key Laboratory of Organic Optoelectronics and Molecular Engineering of the Ministry of Education, Tsinghua University, Beijing, 100084, People's Republic of China.

${ }^{\ddagger}$ Department of Chemistry, Southern University of Science and Technology, Shenzhen 518055, People's Republic of China.

\section{Contents}

I. Physical measurements

II. Supporting figures 


\section{Physical measurements}

Characterization. UV-vis-NIR absorption spectra were recorded on cary5000 (DCM as solvent).. Mass spectrum was recorded on a Waters Q-TOF mass spectrometer equipped with a Z-spray source. The sample was directly infused into the chamber at $5 \mathrm{~mL} \cdot \mathrm{min}^{-1}$. FTIR spectra were recorded on Nicolet Avatar 380 with samples prepared as KBr pellets.

Intensity data of $\mathbf{A g}_{61}$ was collected on a Rigaku Agilent SuperNova Dual system $(\mathrm{Cu} \mathrm{K} \alpha)$ at $173 \mathrm{~K}$. Absorption corrections were applied by using the program CrysAlis (multi-scan). The structure was solved by direct methods, and non-hydrogen atoms except $\mathrm{SbF}_{6}{ }^{-}$counteranions, solvent and water molecules were refined anisotropically by least-squares on $\mathrm{F}_{2}$ using the SHELXTL program. The hydrogen atoms of organic ligands were generated geometrically. And SQUEEZE routine in PLATON was employed in the structural refinements of crystal $\mathbf{A g}_{\mathbf{6}}$, due to large solvent voids in the structures. Crystal data have been deposited in the Cambridge Structural Database, CCDC-2082240. 


\section{Supporting figures}

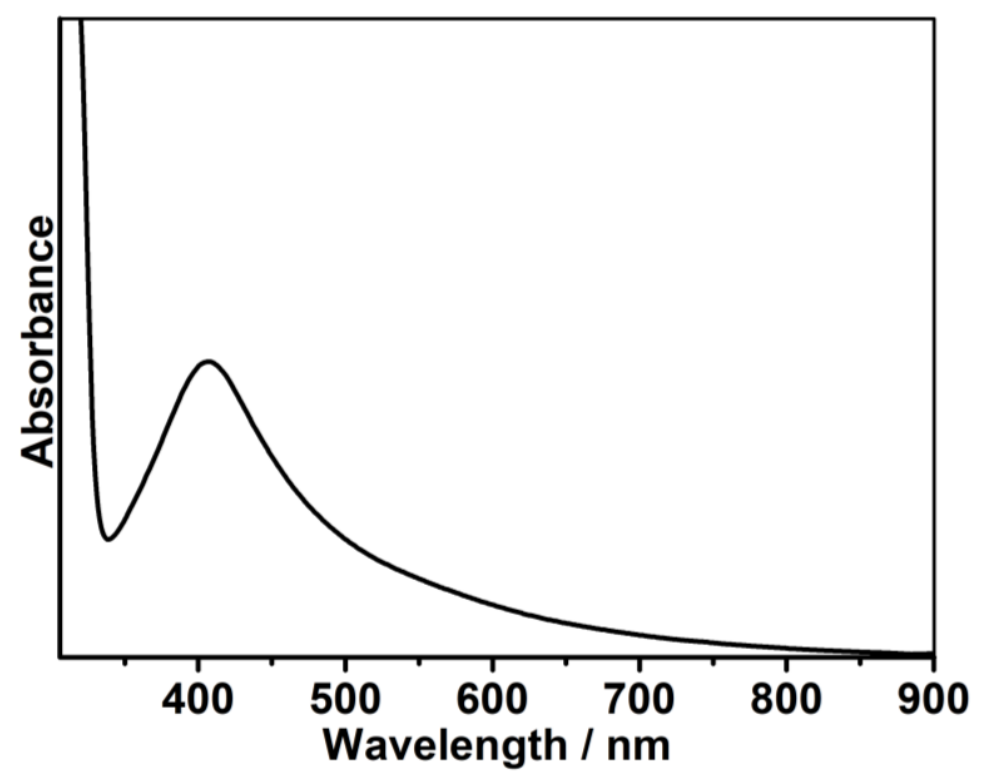

Figure S1. Optical absorption spectra of the crude products reduction with $0.6 \mathrm{mg} \mathrm{NaBH}_{4}$.

a)

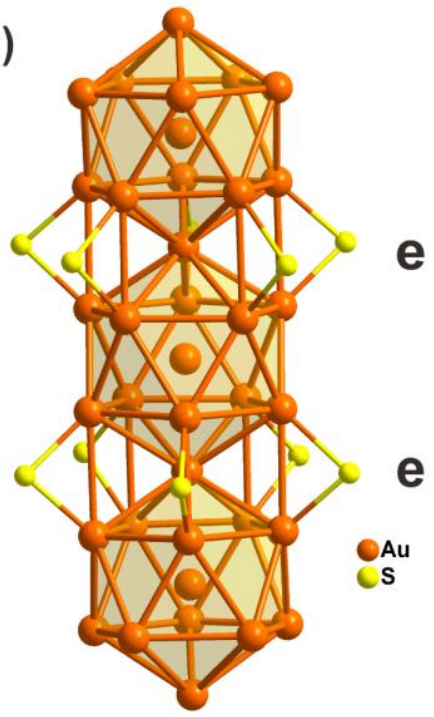

b)

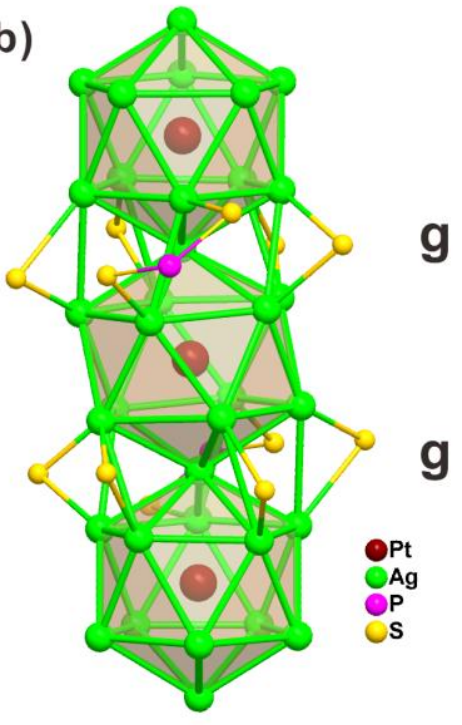

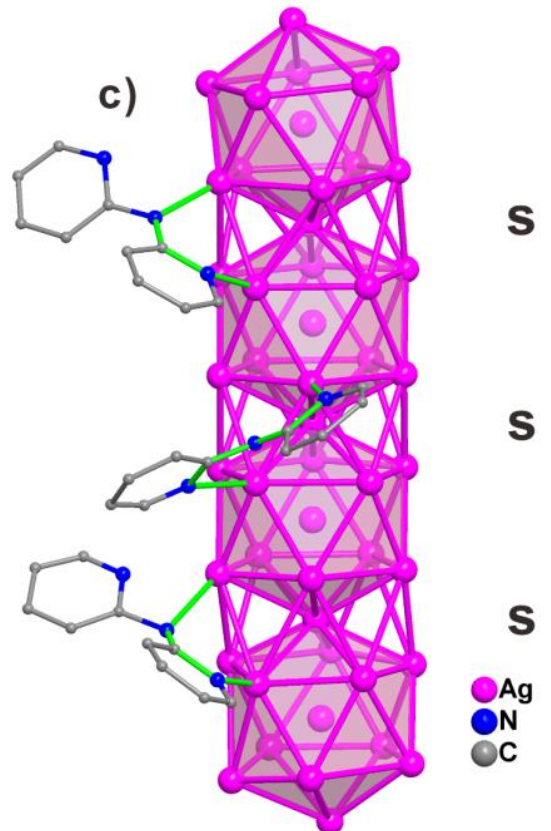

Figure S2. The connection mode of the $\mathrm{M}_{13}$ assembled metal nanoclusters: a) $\left.\left[\mathrm{Au}_{37}\left(\mathrm{PPh}_{3}\right)_{10}\left(\mathrm{SC}_{2} \mathrm{H}_{4} \mathrm{Ph}\right)_{10} \mathrm{X}_{2}\right]^{+}, \mathrm{b}\right) \mathrm{Pt}_{3} \mathrm{Ag}_{44}(\mathrm{dtp})_{22}$ and c) $\left[\mathrm{Ag}_{61}(\mathrm{dpa})_{27}\right]^{4+}(\mathrm{e}=$ eclipsed, $\mathrm{g}=$ gauche, $\mathrm{s}=$ staggered). 
a)

b)

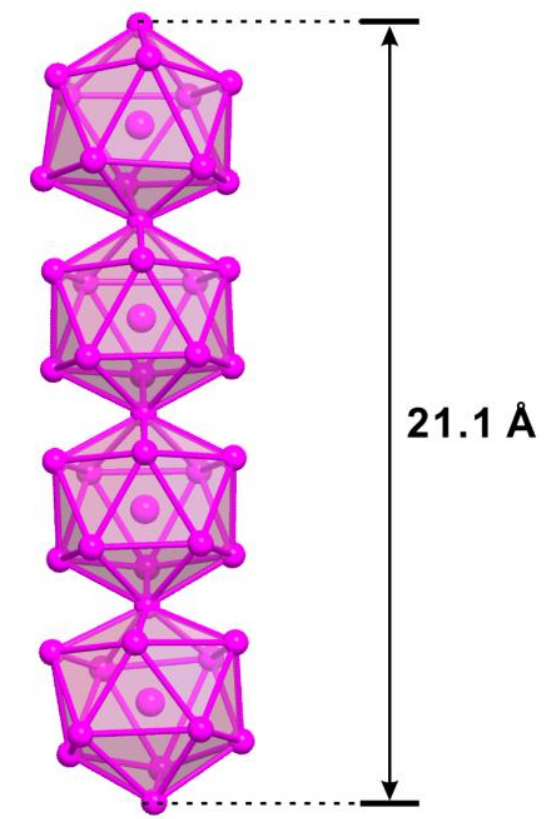

Figure S3. The silver core frameworks of $\mathrm{Ag}_{13}$ assembled $\mathrm{Ag}$ nanoclusters with different numbers of icosahedra: a) $\left[\operatorname{Ag}_{21}(\mathrm{dpa})_{12}\right]^{+}$, b) $\left[\operatorname{Ag}_{61}(\mathrm{dpa})_{27}\right]^{4+}$.

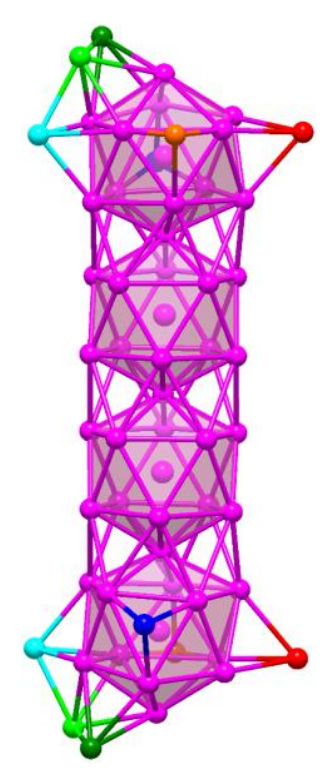

Figure S4. The structure dissection of the core and the capped silver atoms in $\mathbf{A g}_{6 \mathbf{6 1}}$. 
<smiles></smiles>
motif A

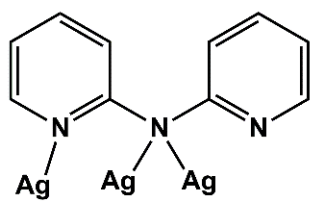
motif C<smiles></smiles>

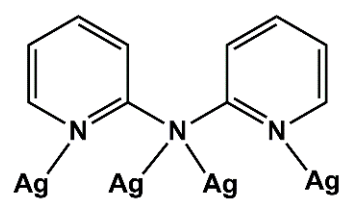

motif D<smiles></smiles>

motif $E$

Figure S5. Binding mode of dpa-Ag systems presented in this work.

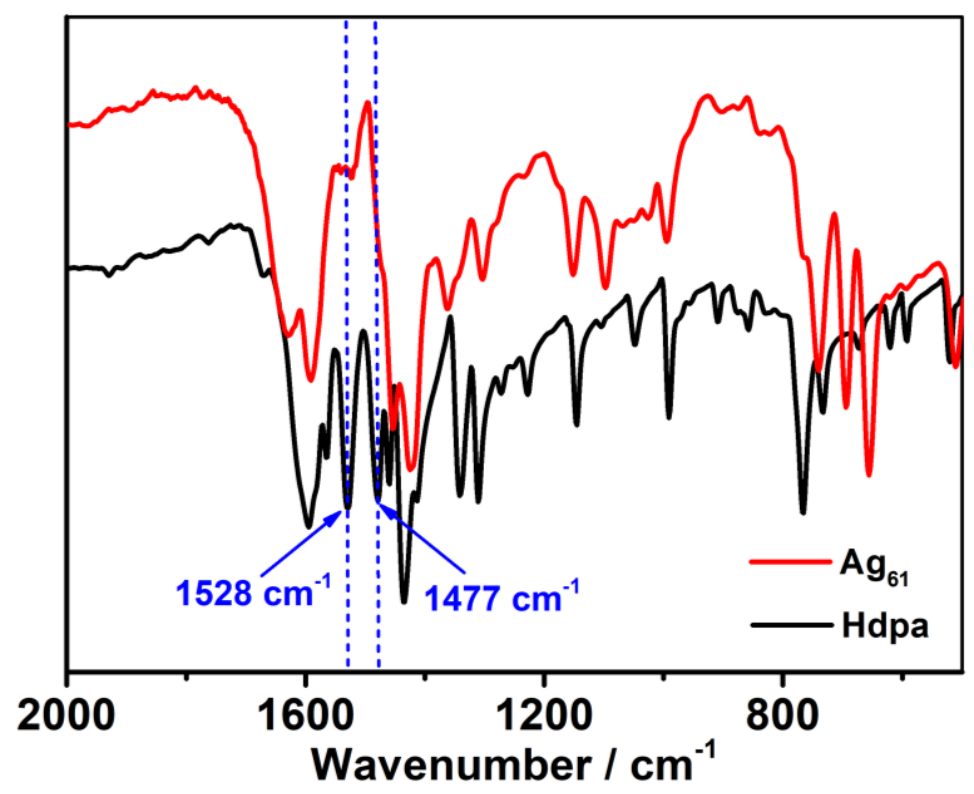

Figure S6. IR spectra of Hdpa (black trace) and Ag61 (red trace). 


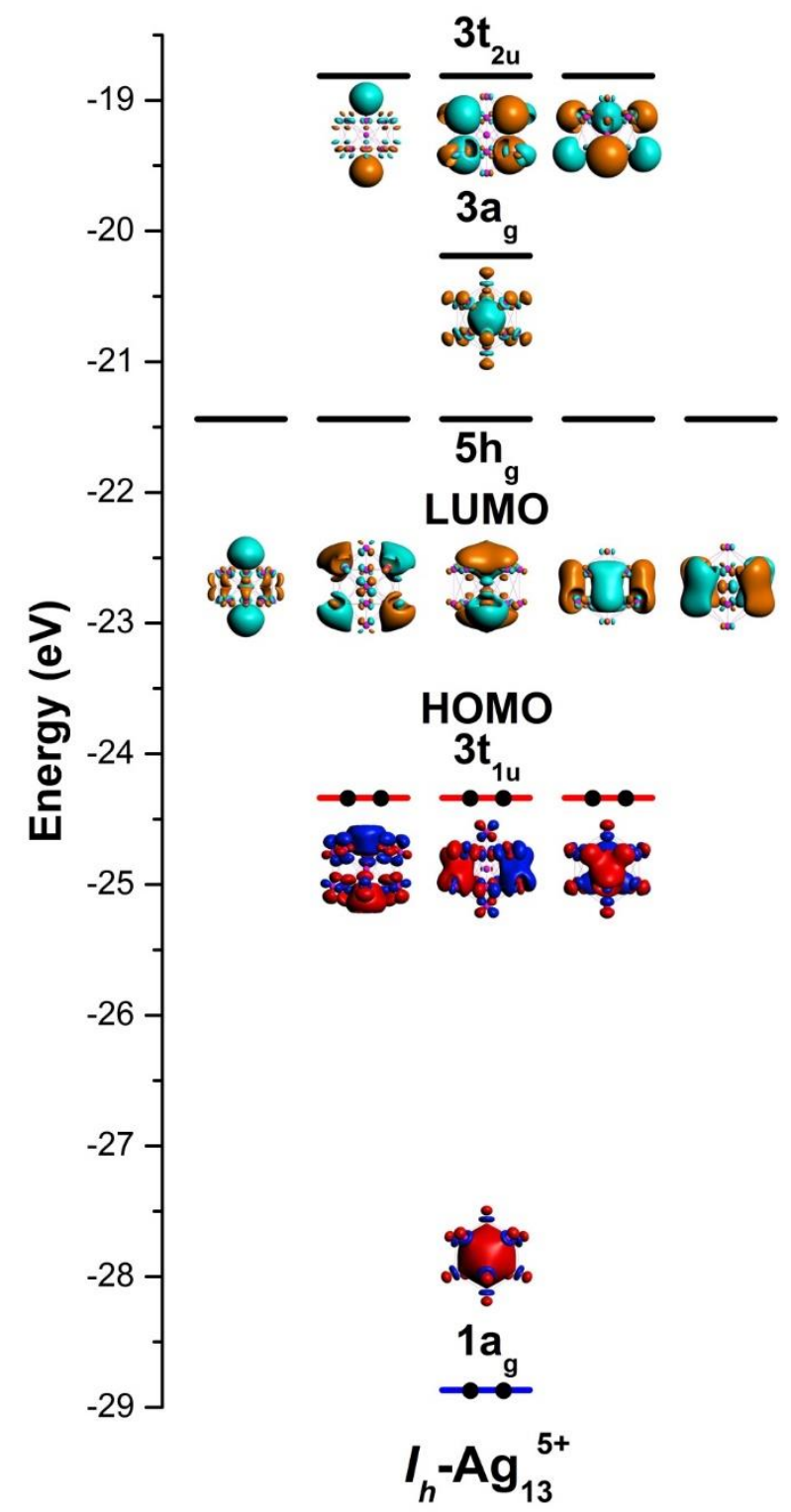

Figure S7. 5s-based orbital energy level diagram and MO contour plots of $I_{h}-\mathrm{Ag}_{13}{ }^{5+}$. Energy levels of $1 \mathrm{ag}$ and $3 \mathrm{t}_{\mathrm{lu}}$ orbitals are shown in blue and red, respectively, while all other orbitals in black. Electrons on the occupied MOs are represented by dots. 


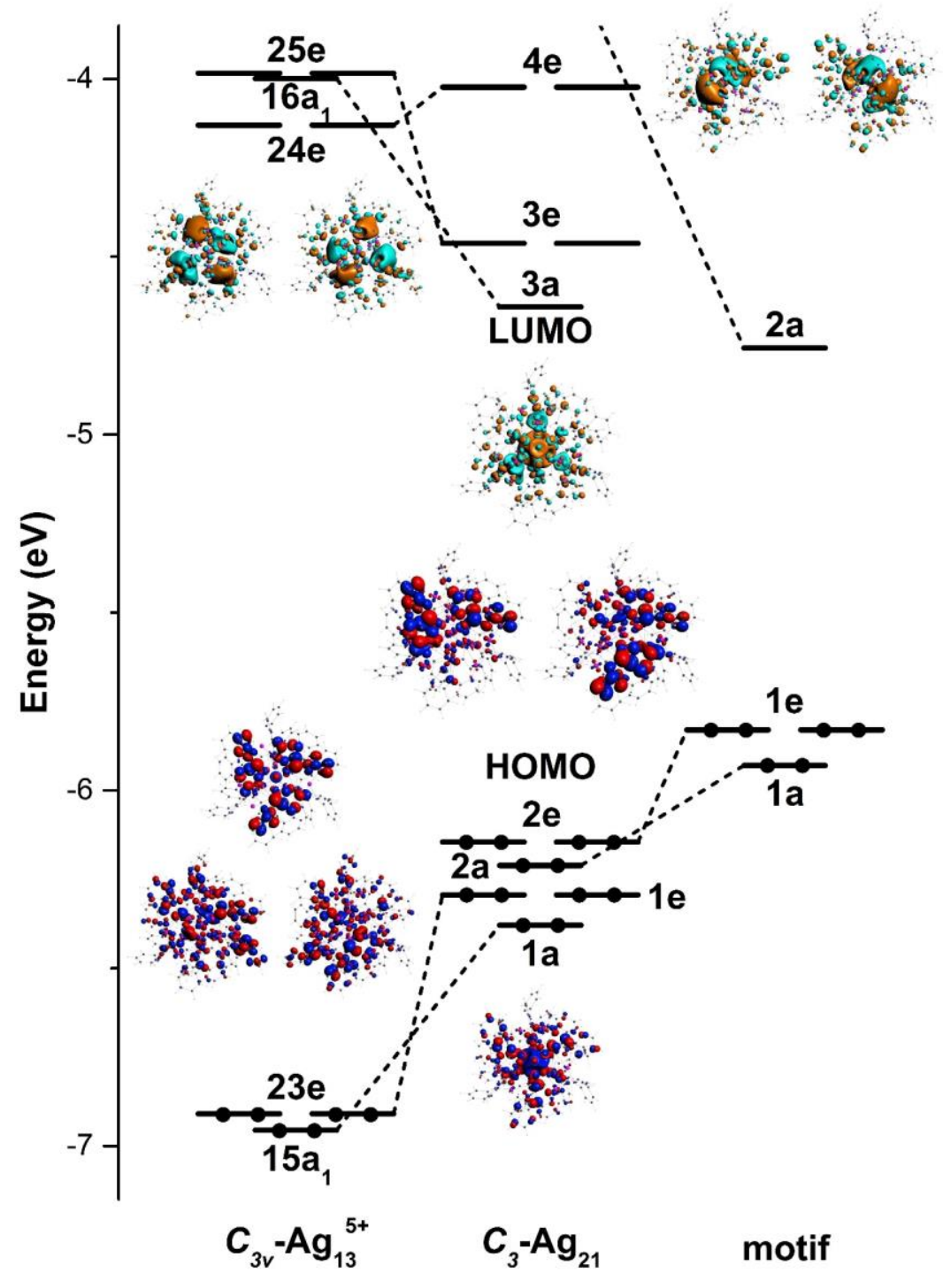

Figure S8. Qualitative MO energy-level correlation diagram of $C_{3 v}-\mathrm{Ag}_{13}{ }^{5+}$ and the dpa-Ag motif for Ag21 from DFT/PBE calculations. Contour plots of MOs for Ag21 are also shown. $3 \mathrm{t}_{1 \mathrm{u}}$ and $5 \mathrm{~h}_{\mathrm{g}}$ orbitals of $I_{h}-\mathrm{Ag}_{13}{ }^{5+}$ split into $15 \mathrm{a}_{1}+23 \mathrm{e}$ and $24 \mathrm{e}+16 \mathrm{a}_{1}+25 \mathrm{e}$ orbitals under $C_{3 v}$ point-group symmetry, respectively. Electrons on the occupied MOs are represented by dots. 


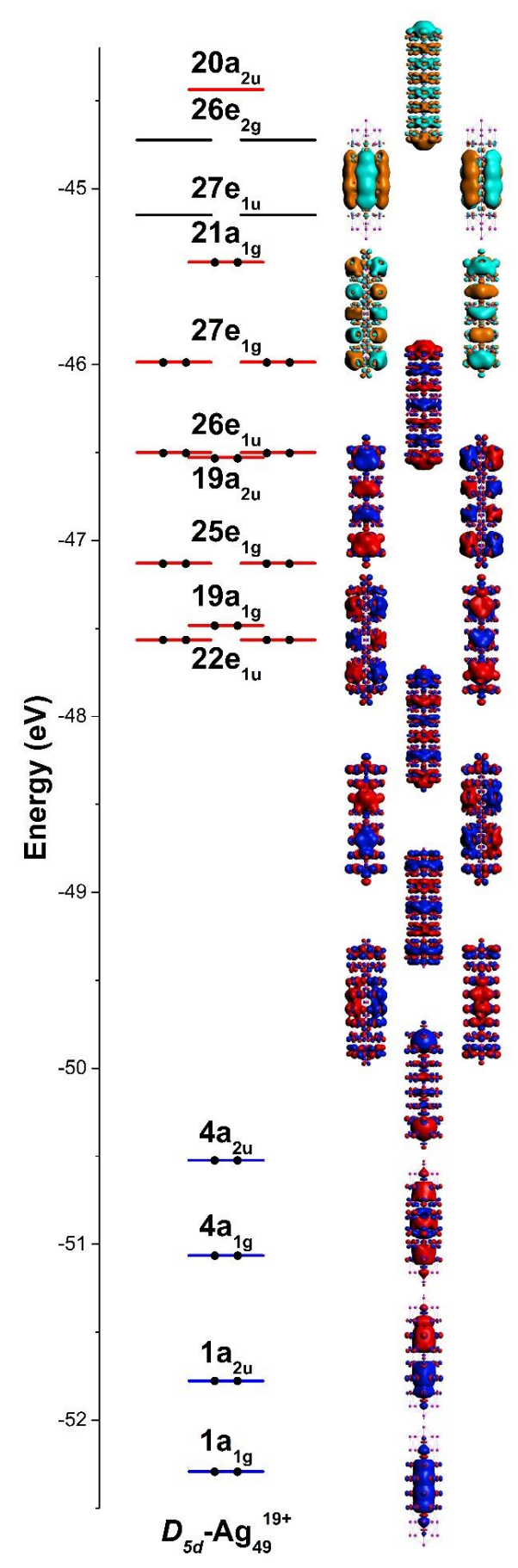

Figure S9. 5s-based orbital energy level diagram and MO contour plots of $D_{5 d}-\mathrm{Ag}_{49}{ }^{19+}$. Interactions between $1 \mathrm{a}_{\mathrm{g}}$ orbitals of four $I_{h}-\mathrm{Ag}_{13}$ units lead to generation of $\left(1 \mathrm{a}_{1 \mathrm{~g}}\right)^{2}\left(1 \mathrm{a}_{2 \mathrm{u}}\right)^{2}\left(4 \mathrm{a}_{1 \mathrm{~g}}\right)^{2}\left(3 \mathrm{a}_{2 \mathrm{u}}\right)^{2}$ configuration with energy levels shown in blue, while those of $3 t_{1 u}$ orbitals produce the $\left(3 \mathrm{a}_{2 \mathrm{u}}\right)^{2}\left(3 \mathrm{e}_{\mathrm{lu}}\right)^{4}\left(25 \mathrm{e}_{\mathrm{lg}}\right)^{4}\left(19 \mathrm{a}_{2 \mathrm{u}}\right)^{2}\left(26 \mathrm{e}_{1 \mathrm{u}}\right)^{4}\left(27 \mathrm{e}_{\mathrm{g}}\right)^{4}\left(21 \mathrm{a}_{1 \mathrm{~g}}\right)^{2}\left(20 \mathrm{a}_{2 \mathrm{u}}\right)^{0}$ configuration with energy levels in red. Electrons on the occupied MOs are represented by dots. 


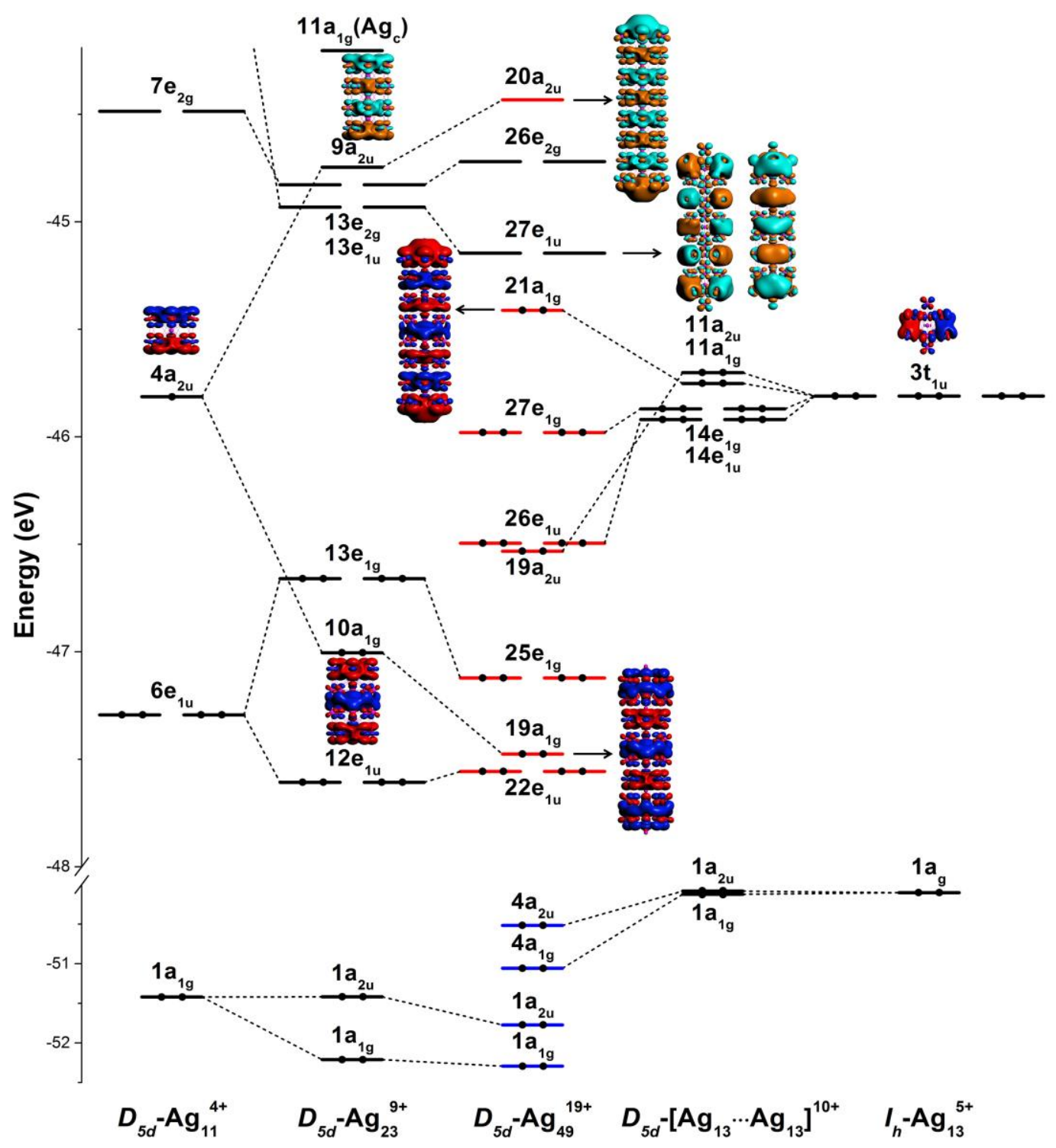

Figure S10. Schematic MO energy-level correlation diagram of $D_{5 d}-\mathrm{Ag}_{23}{ }^{9+}$ and $D_{5 d-}\left[\mathrm{Ag}_{13} \cdots \mathrm{Ag}_{13}\right]^{10^{+}}$ fragments for $D_{5 d}-\mathrm{Ag}_{49}{ }^{19+}$. The $D_{5 d-} \mathrm{Ag}_{49}{ }^{19+}$ core of $\mathbf{A g}_{61}$ is divided into the $\mathrm{Ag}_{13} \cdots \mathrm{Ag}_{13}$ fragment formed by two $\mathrm{Ag}_{13}$ units at two ends of the rod, and the $\mathrm{Ag}_{23}$ fragment in the middle of the rod with two $\mathrm{Ag}_{11}$ units and one central $\mathrm{Ag}$ atom $\left(\mathrm{Ag}_{\mathrm{c}}\right)$. As the $\mathrm{Ag}_{13}$ units locate at two ends of the rod, there are very weak orbital interaction between them, as seen from the moderate energy level splitting from $\mathrm{Ag}_{13}$ to $\mathrm{Ag}_{13} \cdots \mathrm{Ag}_{13}$. For the $\mathrm{Ag}_{23}$ fragment, the electron at the $5 \mathrm{~s}$ of $\mathrm{Ag}_{\mathrm{c}}$ atom is oxidized and denotes to the vacant $11 \mathrm{a}_{1 \mathrm{~g}}$ orbital, leading to formal oxidation state of $\mathrm{Ag}_{\mathrm{c}}$ as +1 . Thus, each drum-like $\mathrm{Ag}_{11}$ unit of the $\mathrm{Ag}_{23}$ fragment can be formally assigned as +4 with 7 valence electrons (Figure S9). In this way, the electron configuration of each icosahedron in the whole $\mathbf{A g}_{61}$ rod is 8e, $7 \mathrm{e}, 7 \mathrm{e}$ and $8 \mathrm{e}$ from one end to the other, respectively.Energy levels of $D_{5 d}-\mathrm{Ag}_{49}{ }^{19+}$ with red and blue 
lines denote to MOs derived from $3 \mathrm{t}_{1 \mathrm{u}}$ and $1 \mathrm{a}_{1 \mathrm{~g}}$ orbitals of $\mathrm{Ih}_{h}-\mathrm{Ag}_{13^{5+}}{ }^{+}$, respectively. Electrons on the occupied MOs are represented by dots.

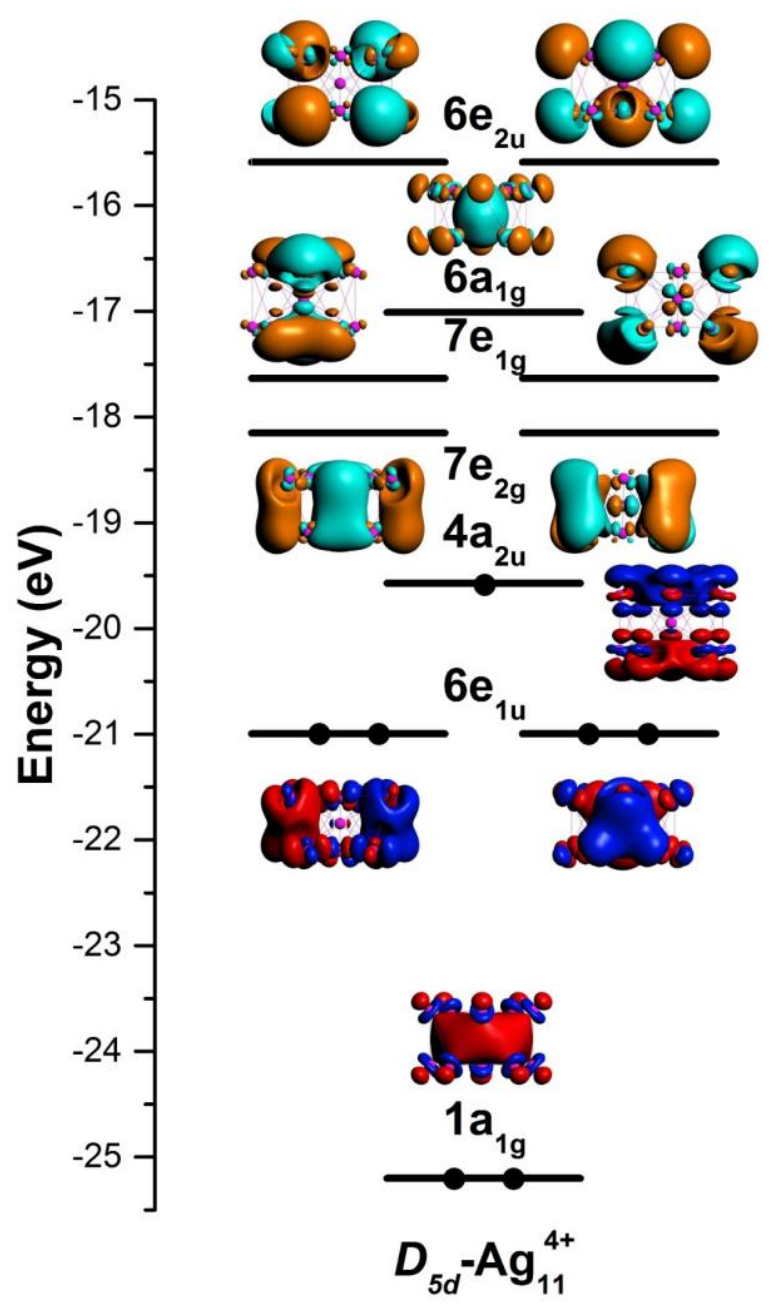

Figure S11. 5s-based orbital energy level diagram and MO contour plots of $D_{5 d}-\mathrm{Ag}_{11}{ }^{4+}$. Electrons on the occupied MOs are represented by dots. 


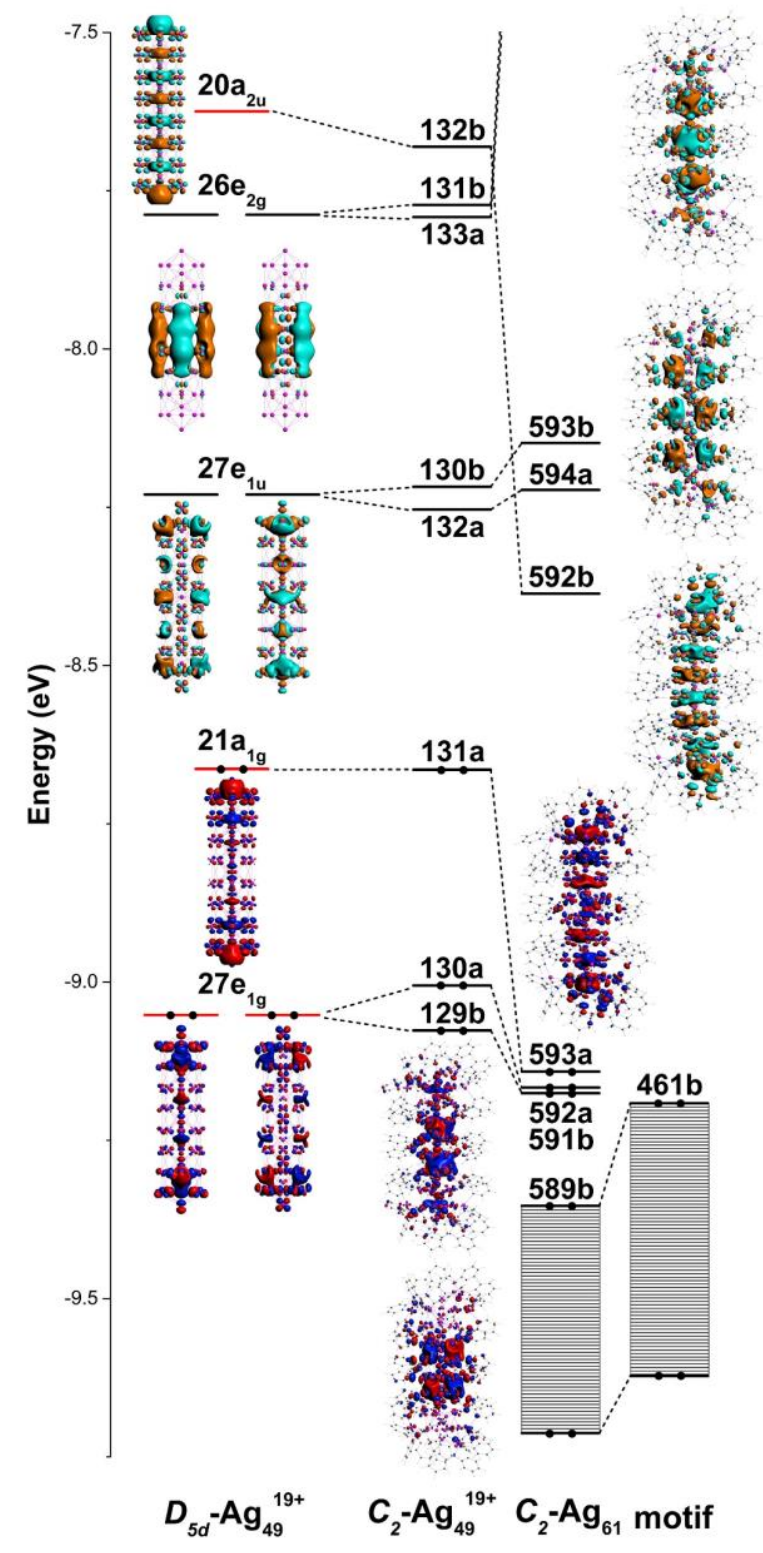

Figure S12. Qualitative MO energy-level correlation diagram of $D_{5 d^{-}}-\mathrm{Ag}_{49}{ }^{19+}, C_{2}-\mathrm{Ag}_{49}{ }^{19+}$ and the dpa-Ag motif for $\mathbf{A g} 61$ from DFT/PBE calculations. Contour plots of MOs for $D_{5 d-} \mathrm{Ag}_{49}{ }^{19+}$ and selected MOs (from 591b to 593b) for $\mathbf{A g}_{61}$ are shown. Energy levels of $D_{5 d}-\mathrm{Ag}_{49}{ }^{19+}$ with red lines denote to MOs derived from $3 \mathrm{t}_{1 \mathrm{u}}$ orbitals of $\mathrm{Ih}_{h}-\mathrm{Ag}_{13}{ }^{5+}$. Electrons on the occupied MOs are represented by dots. 


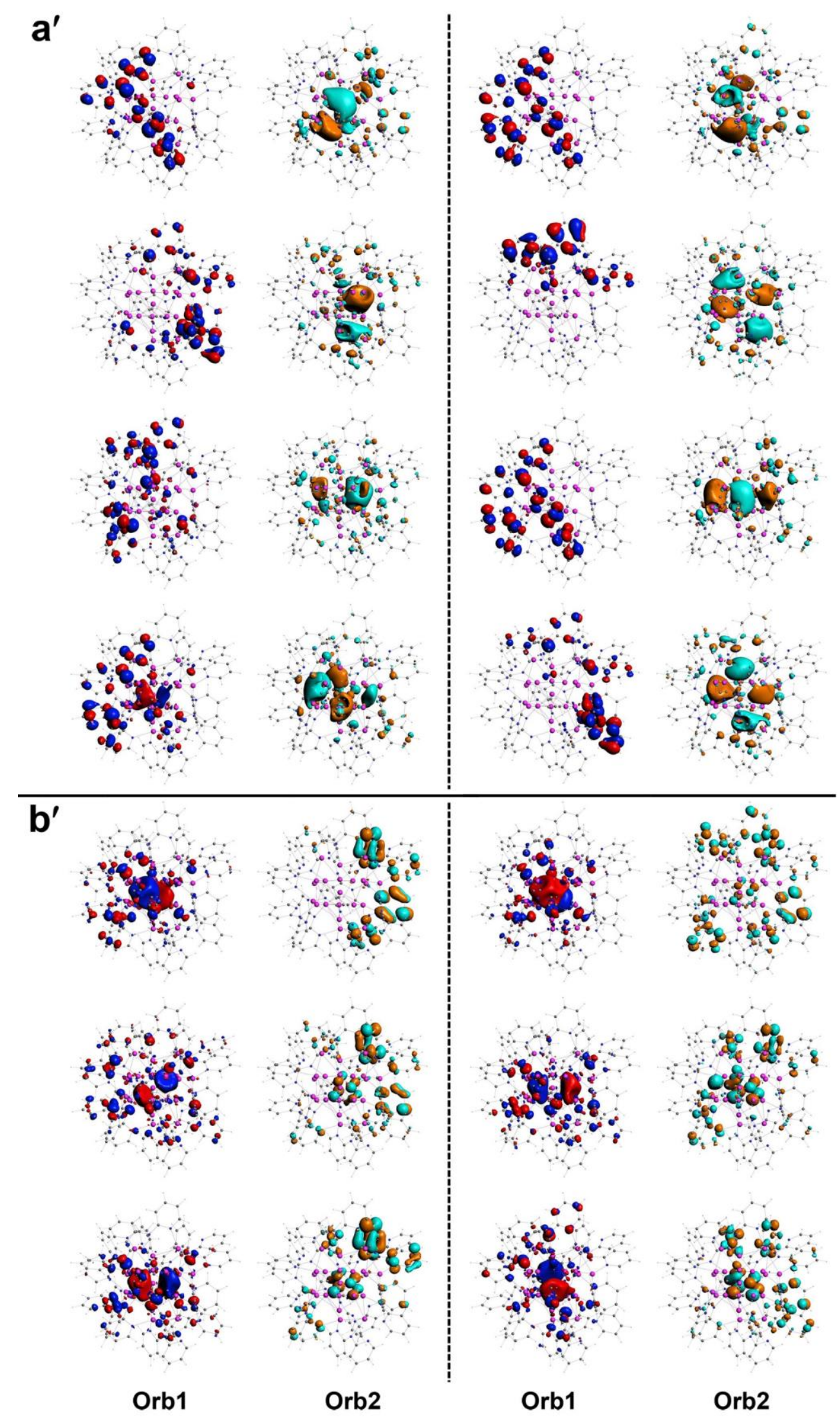

Figure S13. Contour plots of natural transition orbitals (NTOs) of Ag21. The electron transitions are from the occupied orbital (Orb1) to the vacant orbital (Orb2). 


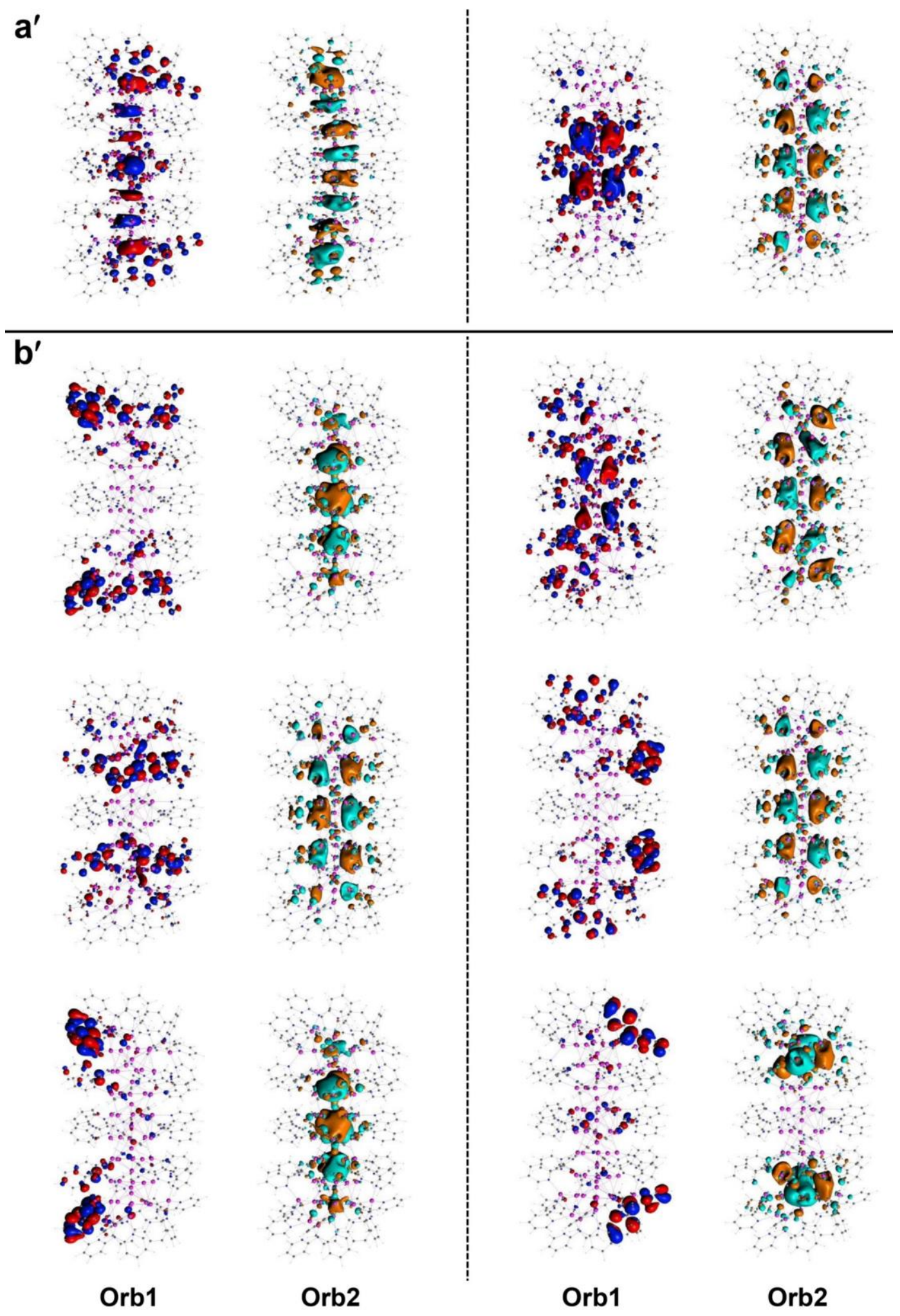

Figure S14. Contour plots of NTOs of Ag61. The electron transitions are from the occupied orbital (Orb1) to the vacant orbital (Orb2). It should be noted that there is one-node difference between the two orbitals for each transition of peak a', i.e., the node is 6 in HOMO and 7 in LUMO while the node is 3 in HOMO-2 and 4 in LUMO +1. 


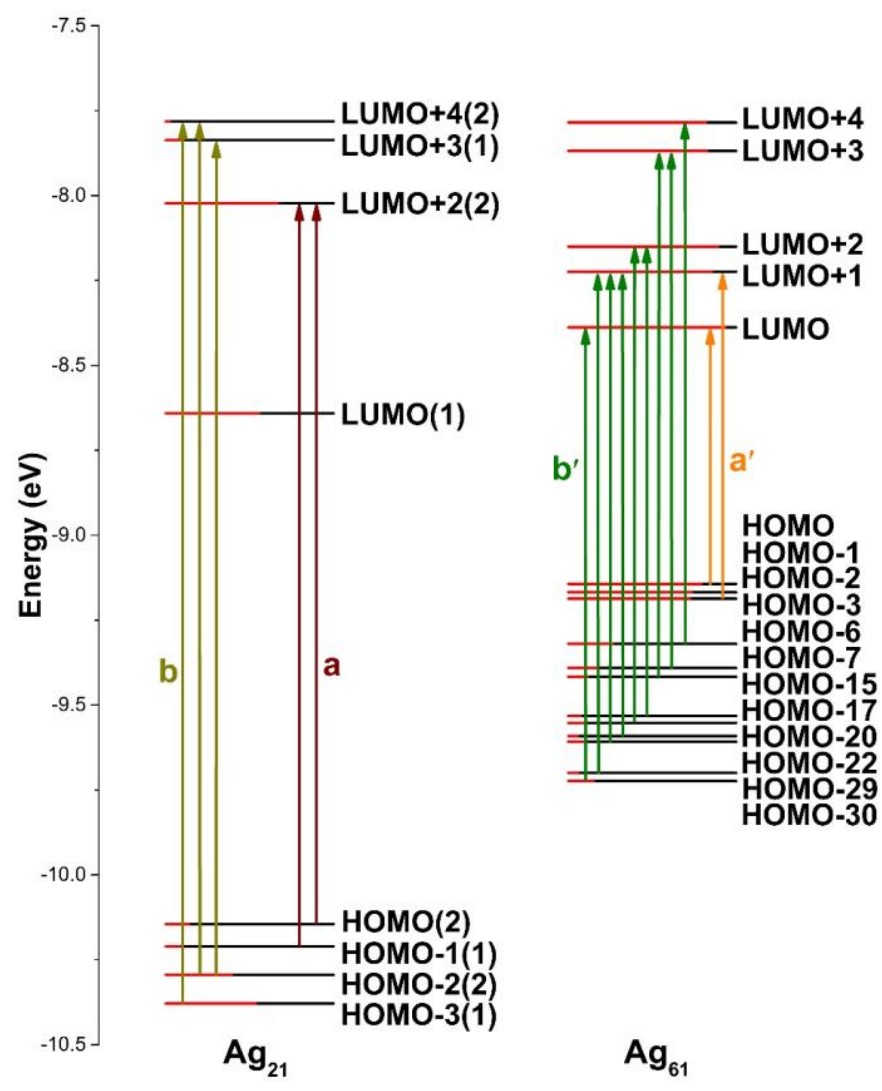

Figure S15. Kohn-Sham orbital energy level diagram of $\mathbf{A g}_{21}$ and $\mathbf{A g}_{\mathbf{6 1}}$ from TDDFT/LB94 calculations, with contributions of the Ag core and the dpa-Ag motif shown in red and black, respectively. Main electron excitations correspond to peaks in the absorption spectra are marked with color arrows and labels. The MOs are all non-degenerate for Ag61 and shown in parenthesis for $\mathbf{A g}_{21}$. 

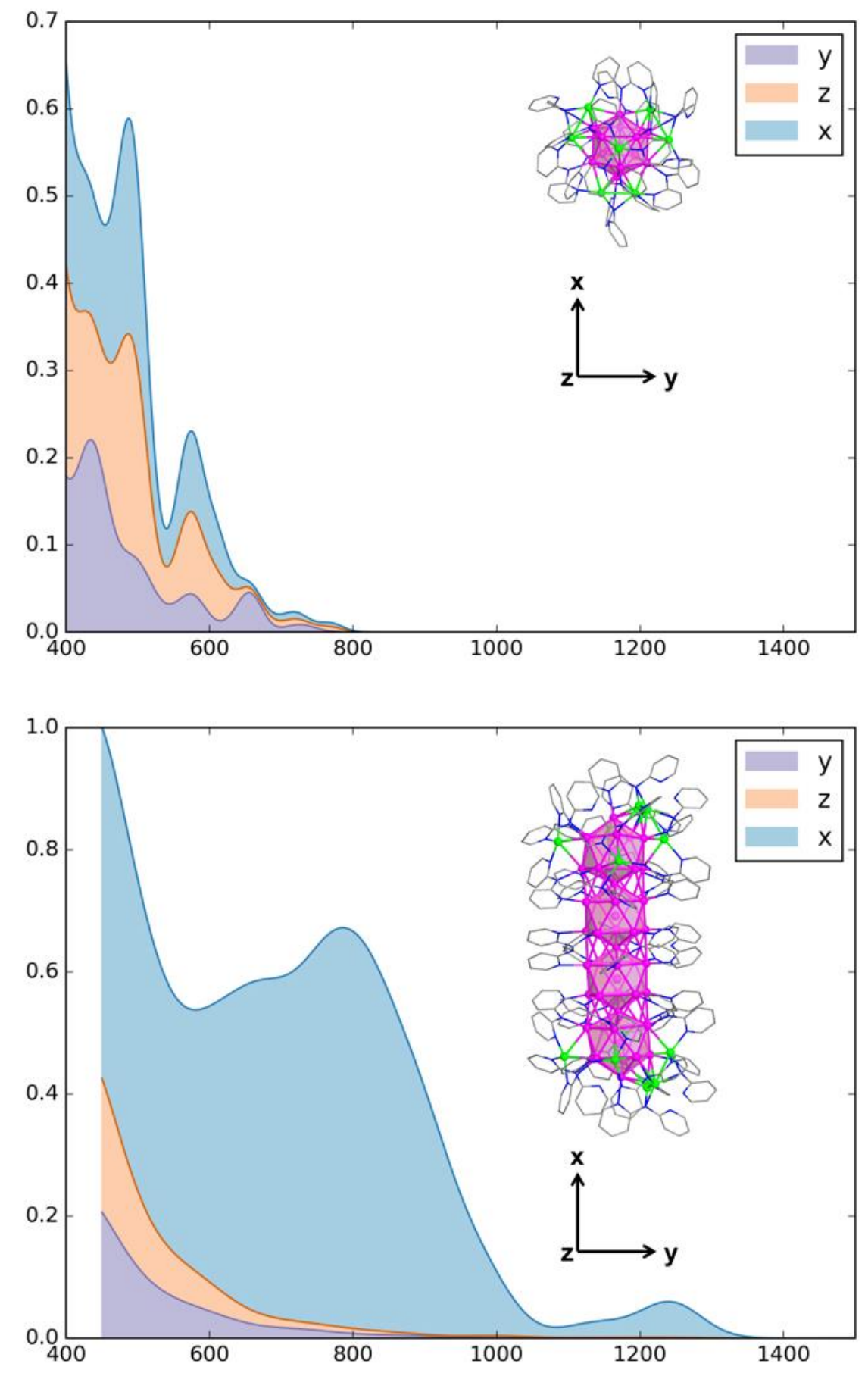

Figure S16. Calculated optical absorption spectra of clusters $\mathbf{A g}_{21}$ and $\mathbf{A g}_{61}$, decomposed to polarization components. The maximum intensities are scaled to unity for each cluster. The $\mathrm{x}$-direction is along the longitudinal axis of the superclusters. 
Table S1. Crystal data and structure refinement for $\mathbf{A g}_{61}$.

Empirical formula

Formula weight

Temperature/K

Crystal system

Space group

$\mathrm{a} / \AA ̊$ Unit cell dimensions

Volume $/ \AA^{3}$

Z

Calculated density $\left(\mathrm{g} / \mathrm{cm}^{3}\right)$

Absorption coefficient $/ \mathrm{mm}^{-1}$

$\mathrm{F}(000)$

Crystal size $/ \mathrm{mm}^{3}$

Radiation

$2 \Theta$ range for data collection/ ${ }^{\circ}$

Index ranges

Reflections collected

Independent reflections

Data/restraints/parameters

Goodness-of-fit on $\mathrm{F}^{2}$

Final R indexes [I $>=2 \sigma(\mathrm{I})]$

Final $\mathrm{R}$ indexes [all data]

Largest diff. peak/hole / e $\AA^{-3}$
$\mathrm{C}_{270} \mathrm{H}_{216} \mathrm{~N}_{81} \mathrm{~F}_{24} \mathrm{Ag}_{61} \mathrm{Sb}_{4}$

12118.29

$173.00(10)$

monoclinic

$C 2 / \mathrm{c}$

$a=29.8768(7) \AA \quad \alpha=90^{\circ}$

$b=57.3100(11) \AA \quad \beta=97.388(2)^{\circ}$

$c=20.6541(5) \AA \quad \gamma=90^{\circ}$

35071.2(14)

4

2.295

29.547

22760.0

$0.03 \times 0.03 \times 0.02$

$\mathrm{CuK} \alpha(\lambda=1.54184)$

7.228 to 122.33

$-33 \leq \mathrm{h} \leq 32,-65 \leq \mathrm{k} \leq 52,-16 \leq 1 \leq 23$

60112

$26881\left[R_{\text {int }}=0.0452, R_{\text {sigma }}=0.0577\right]$

$26881 / 145 / 1968$

1.080

$R_{1}=0.0733, w R_{2}=0.2061$

$R_{1}=0.0975, w R_{2}=0.2242$

$4.91 /-5.79$ 
Table S2. Selected bond lengths (in angstrom) and Mayer bond orders of $\mathbf{A g}_{21}$ and $\mathbf{A g}_{61}$ from DFT/PBE calculations. Ag-Ag bonds of the silver core in the two nanoclusters are classified into inner bonds $\left(\mathrm{Ag}_{\mathrm{c}}-\mathrm{Ag}_{\mathrm{s}}\right)$, shell bonds $\left(\mathrm{Ag}_{\mathrm{s}}-\mathrm{Ag}_{\mathrm{s}}\right)$ and interface bonds. Experimental values are listed in parentheses for comparison.

\begin{tabular}{|c|c|c|c|c|c|}
\hline \multirow{2}{*}{\multicolumn{2}{|c|}{ Bond }} & \multicolumn{2}{|c|}{$\mathbf{A g}_{21}$} & \multicolumn{2}{|c|}{$\operatorname{Ag}_{61}$} \\
\hline & & Bond length & $\mathrm{BO}$ & Bond length & $\mathrm{BO}$ \\
\hline \multirow{2}{*}{ I } & $A g_{c}-A g_{s}$ & $2.832(2.790)$ & 0.23 & $2.858(2.796)$ & 0.22 \\
\hline & $A g_{s}-A g_{s}$ & $2.977(2.933)$ & 0.13 & $3.009(2.944)$ & 0.13 \\
\hline \multicolumn{2}{|r|}{$A g_{I}-A g_{I I}$} & --- & --- & $3.202(3.108)$ & 0.07 \\
\hline \multirow{2}{*}{ II } & $\mathrm{Ag}_{\mathrm{c}}-\mathrm{Ag}_{\mathrm{s}}$ & --- & --- & $2.826(2.766)$ & 0.23 \\
\hline & $A g_{s}-A g_{s}$ & --- & --- & $2.973(2.910)$ & 0.14 \\
\hline \multicolumn{2}{|r|}{$\mathrm{Ag}_{\mathrm{II}}-\mathrm{Ag}_{\mathrm{III}}$} & --- & --- & $3.162(3.086)$ & 0.07 \\
\hline \multirow{2}{*}{ III } & $A g_{c}-A g_{s}$ & --- & --- & $2.826(2.766)$ & 0.23 \\
\hline & $\mathrm{Ag}_{\mathrm{s}}-\mathrm{Ag}_{\mathrm{s}}$ & --- & --- & $2.973(2.910)$ & 0.14 \\
\hline \multicolumn{2}{|r|}{$\mathrm{Ag}_{\mathrm{III}}-\mathrm{Ag}_{\mathrm{IV}}$} & --- & --- & $3.202(3.108)$ & 0.07 \\
\hline \multirow{2}{*}{ IV } & $\mathrm{Ag}_{\mathrm{c}}-\mathrm{Ag}_{\mathrm{s}}$ & --- & --- & $2.858(2.796)$ & 0.22 \\
\hline & $\mathrm{Ag}_{\mathrm{s}}-\mathrm{Ag}_{\mathrm{s}}$ & --- & --- & $3.009(2.944)$ & 0.13 \\
\hline \multicolumn{2}{|r|}{$A g_{\text {cap }}-A_{g_{\text {ker }}}$} & $2.940(2.867)$ & 0.11 & $2.941(2.900)$ & 0.10 \\
\hline \multicolumn{2}{|r|}{ Ag-N } & $2.323(2.248)$ & 0.24 & $2.306(2.261)$ & 0.24 \\
\hline
\end{tabular}


Table S3. The average Mulliken charges of silver atoms and dpa ligands of $\mathbf{A g}_{21}$ and $\mathbf{A g}_{61}$ clusters.

\begin{tabular}{c|c|c}
\hline Atom & Ag21 & Ag61 \\
\hline $\operatorname{Ag}($ silver core $)$ & 0.27 & 0.24 \\
\hline $\operatorname{Ag}($ dpa-Ag motif $)$ & 0.50 & 0.52 \\
\hline $\mathrm{dpa}$ & -0.54 & -0.52 \\
\hline
\end{tabular}


Table S4. Experimental and computed peak positions (in $\mathrm{nm}$ ) in the optical absorption spectra.

\begin{tabular}{c|c|c|c}
\hline Nanocluster & Peak & TDDFT & Exp. \\
\hline \multirow{2}{*}{$\operatorname{Ag}_{21}$} & $\mathrm{a}$ & 574 & 520 \\
\cline { 2 - 4 } & $\mathrm{b}$ & 487 & 422 \\
\hline \multirow{2}{*}{$\mathbf{A g}_{61}$} & $\mathrm{a}^{\prime}$ & 1239 & 1170 \\
\cline { 2 - 4 } & $\mathrm{b}^{\prime}$ & 785 & 819 \\
\hline
\end{tabular}

